\title{
Attachment figures when death is approaching: a study applying attachment theory to adult patients' and family members' experiences during palliative home care
}

\author{
Anna Milberg ${ }^{1,2,3}$ (D) Maria Friedrichsen ${ }^{1,2,3}$
}

Received: 5 August 2016 / Accepted: 6 February 2017 / Published online: 20 February 2017

(C) The Author(s) 2017. This article is published with open access at Springerlink.com

\begin{abstract}
Purpose Attachment theory is currently receiving much attention in relation to how adults cope with severe illness. The study aims were using the experiences of patients and family members to explore attachment figures (a central concept within the theory) during palliative home care.

Methods Twelve patients and 14 family members were interviewed during ongoing palliative home care. The interviews were analysed using qualitative content analysis.

Results Four types of attachment figures were identified: (i) family and friends, (ii) health care practitioners, (iii) pets and (iv) God. Both non-physical and physical contact with the attachment figures facilitated a sense of security. In addition, the patient/family members and their attachment figures were described by some as a "we", and when one part of the "we" felt insecure, this made the other also feel insecure. The patients' unstable and progressing illnesses constituted a threat to the patients' and family members' sense of security. The availability of the attachment figures made them feel secure, and they could then divert their attention from the patients' illnesses to other things in everyday life, e.g. socialising with family and friends. Some family members also had to cope
\end{abstract}

Anna Milberg

anna.milberg@liu.se

1 Department of Social and Welfare Studies, Linköping University, Norrköping, Sweden

2 Department of Advanced Home Care and Department of Social and Welfare Studies, Vrinnevi hospital, Linköping University, 601 82 Norrköping, Sweden

3 Palliative Education \& Research Centre, and Department of Social and Welfare Studies, Vrinnevi hospital, Linköping University, 601 82 Norrköping, Sweden with the loss of their own attachment figure, when the patient, who had previously been a source of security for them, was no longer able to offer protection and comfort due to the progression of the illness.

Conclusion Important aspects of attachment figures in the end-of-life context were identified, and their clinical implications will be discussed.

Keywords Attachment figure $\cdot$ Palliative $\cdot$ Attachment theory $\cdot$ Patient $\cdot$ Family member

\section{Introduction}

Attachment theory $[1,2]$ is currently receiving much attention in relation to how adults cope with severe illness and loss [3-10] and how health care practitioners can facilitate patients' and family members' adaptation to such challenging situations $[11,12]$. The purpose of the attachment system is to protect a person from danger [2]. When a human, young or old, is exposed to a threat (actual or symbolic), the attachment system is activated, and he or she will feel a need to seek and re-establish closeness (actual or symbolic) with an attachment figure.

An attachment figure is "a target for proximity-seeking, functions as a "safe haven" in times of need (i.e. he/she reliably offers protection, comfort, support and relief), serves as a "secure base" in a safe environment (i.e. letting the person engage in non-attachment goals and activate other behavioural systems), and an attachment figure's real or expected disappearance induces "separation distress" (i.e. people respond with severe discomfort to actual or potential unwelcome separations from or losses of an attachment figure" [2].

According to attachment theory, individuals are supposed to refer to their attachment figures during the whole life cycle [13], e.g. serious illness will routinely activate attachment 
behaviours in patients and family members, due to threats such as progressive physical disability, declining capacity for self-sufficiency, increasing dependency needs and threats of separation $[2,13,14]$. When the goal of felt security is achieved, the attachment system is deactivated and the individual can peacefully return to non-attachment activities, such as exploration [2].

During early childhood, primary caregivers (usually one or both parents) often have attachment functions [2]. In later childhood and in adulthood, a wider variety of relationship partners can have attachment functions, including siblings, close friends, romantic partners and therapists $[2,15,16]$. Adults often rely on a network of attachment figures, and the importance placed on different figures changes in response to ageing and normative life events [16]. For example, in older adults with grown children, there might be a role-reversal process, and the grown children may begin to serve as attachment figures [17]. It appears also that pets, God and deceased loved ones may become sources of attachment security [16, 18-23]. In addition, it has been proposed that health care practitioners in different settings can serve as attachment figures [6, 24-27], e.g. doctors to patients with cancer [26, 27]. Paralleling the infant-caregiver dynamic, it is thought that the patient develops a model of the practitioner-patient relationship in which the self is viewed as valuable and worthy of care, and the health care provider is regarded as available and compassionate [26].

Although a few reports have offered some suggestions [26, 27] to our knowledge, there are no reported studies with a specific focus on attachment figures in the end-of-life context. It seems important that palliative care teams are aware of what the repertoire of attachment figures may be, in order to facilitate deactivation of the attachment system and allow creative exploration among patients and family members during palliative care. Therefore, the goal of this study, using the experiences of patients and family members, was to explore attachment figures during palliative home care.

\section{Methods}

\section{Participants and setting}

Adult patients $(n=12)$ and adult family members $(n=14)$ were chosen utilising the purposive sampling technique, using background variables in order to get as broad a range of the phenomena as theoretically possible. The study population consisted of a separate, unconnected sample of patients and family members, who were recruited from eight different units providing palliative home care in Sweden (advanced palliative home care teams $(n=3)$; primary care-based teams $(n=5))$. The characteristics of the informants are presented in Tables 1 and 2.
Table 1 Patient characteristics. Twelve patients were interviewed during ongoing palliative home care

\begin{tabular}{|c|c|}
\hline Women $(n)$ & 4 \\
\hline Age in years (median (range)) & $64(35-79)$ \\
\hline Married or cohabiting/living alone $(n)$ & $10 / 2$ \\
\hline \multicolumn{2}{|l|}{ Diagnosis $(n)$} \\
\hline Prostate cancer & 3 \\
\hline Lung cancer or mesothelioma & 2 \\
\hline Gynaecological cancer & 1 \\
\hline Other origin of malignancy & 2 \\
\hline Ischaemic heart disease & 2 \\
\hline Neurologic disease & 1 \\
\hline \multicolumn{2}{|l|}{ Time since diagnosis $(n)$} \\
\hline $1-3$ months $/>3$ months/not responded $(n)$ & $4 / 6 / 2$ \\
\hline \multicolumn{2}{|c|}{ Duration in palliative home care at the time of the interview $(n)$} \\
\hline $1-3$ months $/>3$ months/not responded $(n)$ & $2 / 9 / 1$ \\
\hline \multicolumn{2}{|l|}{ "Last week I ..." (n) } \\
\hline Managed to stay up about half the day & 3 \\
\hline Managed to stay up most of the day & 8 \\
\hline Not responded & 1 \\
\hline \multicolumn{2}{|c|}{ "I have during the palliative home care period $\ldots$ ". $(n)$} \\
\hline Most of the time felt insecure & 0 \\
\hline Sometimes felt secure, sometimes insecure & 1 \\
\hline Most of the time felt secure & 10 \\
\hline Not responded & 1 \\
\hline
\end{tabular}

The advanced palliative home care teams were multidisciplinary and included a physician, 24-h services and access to a back-up ward. The primary care-based teams consisted of a palliative consultant and a specialist nurse available during daytime. The typical length of care was 3 months. The frequency the team members visit the patients may vary during the time in palliative home care depending on the patients' and the family member's needs, from regular telephone contact and no planned visits, to several visits per day.

We have previously, within our larger project about patients' and family members' sense of security during palliative care, reported on palliative home care as a secure base [4]; in the current study, the specific focus will be on attachment figures in the palliative care context.

\section{Data collection and analysis}

Possible participants were individually asked by staff whether they were interested in taking part in the study. An interview guide was developed [28]. Since the concept "attachment figure" would be unfamiliar, theoretical and too complex to easily comprehend for most of the informants, they were not explicitly asked about who their attachment figures were in the interviews. Instead, the interviewers asked questions concerning their possible experience of feeling secure/ 
Table 2 Family member characteristics. Fourteen family members (i.e. the informants) were interviewed during the ongoing palliative home care of a dying family member or friend (i.e. the patient receiving palliative home care)

\begin{tabular}{ll}
\hline Women $(n)$ & 11 \\
Age in years (median (range)) & $69(53-79)$ \\
Married to the patient/child $(n)$ & $13 / 1$ \\
Patients' age in years (median (range)) & $70(61-83)$ \\
Patients' gender (number of women/men) & $4 / 10$ \\
Patient's disease (n) & 5 \\
Prostate cancer & 2 \\
Lymphoma & 2 \\
Gastrointestinal cancer & 1 \\
Gynaecological cancer & 1 \\
Brain tumour & 1 \\
Cancer with unknown origin & 1 \\
Ischaemic heart disease & 1 \\
Neurologic disease & \\
Duration of patient being cared for by palliative home care at the time of \\
the interview $(n)$ & $2 / 2 / 9 / 1$ \\
$<1$ month/1-3 months/>3 months/not responded $(n)$ & \\
I have during the palliative home care period & 1 \\
Most of the time felt insecure & 2 \\
Sometimes felt secure, sometimes insecure & 10 \\
Most of the time felt secure & 1 \\
Not responded & \\
\hline
\end{tabular}

insecure during palliative home care. In the Swedish language, the concept of "security" ("trygghet" in Swedish) is a word used in everyday language, with a broad meaning, describing a psychological state similar to the consequence of a wellfunctioning attachment system, i.e. the concept of "felt security" [29]. Open-ended questions included the following: "Have you experienced a situation when you felt secure/ insecure during the care?", "Have you experienced aspects that facilitated security/insecurity? If so, what or who prompted these feelings?", "(When insecure) How did you manage the situation?" Tape-recorded interviews (about 3090 min; May 2007 to Nov. 2008) were performed by four senior palliative care nurses and were transcribed verbatim by a secretary.

In this study, a deductive content analysis was conducted using "attachment figure" as a theory derived concept to be explored in a new context (palliative home care). This is in accordance with the idea of "directed content analysis", in which "existing theory or research can help focus the research question" [28]. The definition of an attachment figure (described in the "Introduction" section [2]) was used as an operational definition. The analysis was performed using the following steps $[28,30]$ : (i) all transcribed interviews were read through repeatedly to obtain an initial sense of the whole; (ii) a categorisation matrix was developed, based on the operational definition of "attachment figure" (see above); (iii) the interviews were re-read systematically, line by line, and reviewed for content that corresponded to the operational definition of "attachment figure", i.e. identification of significant text segments, or "meaning units"; (iv) each meaning unit was assigned an inductively developed code. The various codes were compared and sorted, according to differences and similarities, into categories, from which broader themes (a theme being a thread of underlying meaning through condensed meaning units, codes or categories, on an interpretative level [30]) were developed inductively. Final content descriptions (abstractions) and relationships with other categories and themes were then developed.

The interview guide and the operational definition of an attachment figure were developed through discussions between the authors. Coding and development of the categories were mainly carried out by the first author. The tentative categories were discussed, revised, and validated in discussion with the other author by supplementing and contesting each other's readings and pre-understandings as part of the reflexivity process [30,31]. The study was approved by the local research ethics committee (Dnr: 144-06) and the study have been performed in accordance with the ethical standards as laid down in the 1964 Declaration of Helsinki and its later amendments. Informed consent was obtained by all individuals participants included in the study.

\section{Results}

To start with, interviews with the patients and with the family members were analysed separately. However, there was extensive overlap in the results of the two groups, indicating a shared experience of what constituted an attachment figure in the context of palliative home care, irrespective of whether the subject was a patient or a family member. The findings are therefore presented in the same manuscript. Six categories and three themes emerged in the analysis of the interviews: see overview in Fig. 1.

\section{Who were the attachment figures?}

When the informants felt insecure and vulnerable, access to attachment figures gave them the sense that there was someone outside themselves that they could trust to be able to manage the challenging situations in the end-of-life context. Four types of attachment figures were identified in the interviews.

\section{(a) Family members and friends}

Family members and friends were important attachment figures whom patients and family members 
Fig. 1 Overview of the findings regarding attachment figures in the end-of-life context according to the patients' and family members' experiences during palliative home care
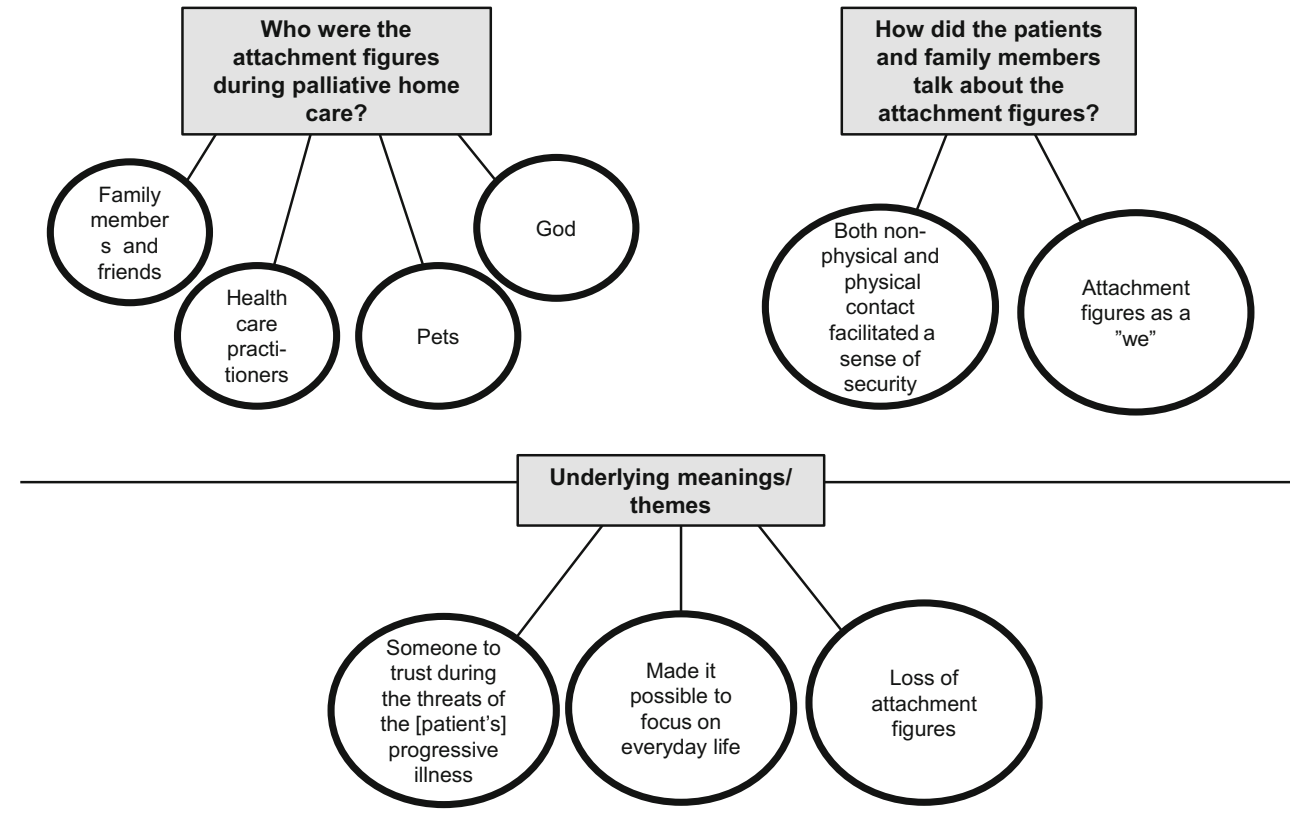

experienced that they could turn to in times of need- to talk, receive emotional or practical support or sit together in silence. These relationships were described as close ones, most often with a husband or wife, but adult friends and grown-up children were also mentioned. Facilitators for developing such deep, comforting relationships were having gone through difficulties as well as joys together, physical and emotional closeness.

If my wife and my children abandoned me, then I would feel very insecure // I think that would be the worst thing that actually can happen. // I can rely on them, always phoning, always get in touch, they will always be there for me as long as I am alive. And that gives me a comforting feeling of security (61-year-old man with lung cancer).

\section{(b) Health care practitioners}

Different health care professionals were mentioned with whom the participants had developed relationships of trust, these being mainly nurses and doctors, and also members of the home care staff. Facilitation of such relationships involved repeated contact, that the practitioner was attentive and responsive to the patient's/family member's situation as a whole (e.g. recognising the person beyond the illness), and that he or she had shown an ability to handle the end-of-life situation (e.g. competence in symptom management). Aspects such as similarities in age and gender were also mentioned as facilitators for the development of such an attachment.

For some of the informants, this kind of trust could be both at an individual level and at a service level, i.e. the informants stated that through trustful interactions with individual practitioners, they could over time develop a sense of security in relation to the service unit as a whole. They trusted that the practitioners would report important aspects of their situation to each other (quotation below). However, some of the patients/family members interviewed described their need to have contact with only a small number of staff members.

Interviewer: Is there any situation or occasion when you have sensed security with having palliative home care? Family member: Yes, it is $\mathrm{N}$ [a nurse]. $\mathrm{N}$ is almost always there, or one of her stand-ins. That is the best feeling of security (wife of a patient with generalised prostate cancer).

(c) Pets

Some informants mentioned that a long-lasting close relationship with a loved pet, e.g. a cat or a dog, had a great effect on their sense of security. Facilitators for such a relationship with a pet were as follows: the pet paying attention to the informant, showing joy when together with him/her and wanting to be close to him/her irrespective of the illness or the informant's feelings of sadness or exhaustion. This kind of contact made the participants feel calm and gave them an inner sense of security.

As I said before, my feeling of security is strongest here at home // [where I have my family and] my dogs; they 
[the dogs] contribute so much to my well-being... they are not only plain company, they make me feel good (62-year-old man with prostate cancer).

\section{(d) God}

A few of the informants described how they felt secure because of their faith. A facilitator of this security was the relationship they experienced with God, e.g. in their prayers, and also through supportive contact with other members of the communion, or with nuns.

I have my faith in God, it gives me my sense of security (79-year-old wife of a patient with gastrointestinal cancer).

\section{How did the patients and family members talk about the attachment figures?}

(a) Both physical and non-physical contacts facilitated a sense of security

The comforting contact with the attachment figure could be of a physical or a non-physical nature. A non-physical contact might be to think of the attachment figure, to look at a picture of him/her, or to hear his/her voice over the phone, e.g. the informant's children living in another city, or practitioners at the palliative care unit. To be comforted by a non-physical contact, it was important that the patient/family member trusted that they could get in touch with this person if there was an acute need, and could get help irrespective of day and time. Such a sense was facilitated when the attachment figure, e.g. the children or practitioners, explicitly expressed to the patient or family member that they really cared and wanted her/him to contact them if any problem should arise.

At times of great threat, e.g. the patient deteriorating or experiencing sudden symptoms, the patient/family member expressed a need for closer proximity to the attachment figure, e.g. to have a nurse, close family members or loved pets physically present in order to relax and have a sense of security, or the patient being cared for on a ward to have quick access to staff members.

\section{(b) Attachment figure as part of a "we"}

The attachment between a patient/family member and an attachment figure was by some informants described as being so close that the two individuals became almost merged into a "we" with each other (first quotation below). What happened to the other individual as a part of this "we" had a direct and major impact on both individuals' feelings of security, e.g. when one individual or part of the "we" felt secure, this also made the other feel secure (second quotation).

We had an appointment [with the doctor] the next day; we always say "we", "we have taken the pills, says my husband". It sounds a bit strange, because he is the one taking them. But we are "we" (wife of a patient with generalised prostate cancer).

When they come regularly, it gives us a sense of security. When I know he feels secure, then I automatically feel secure too (79-year-old wife of a patient with gastrointestinal cancer).

A "we" relationship was most often described by the informants as a relationship with a husband or wife, but such strong closeness was also expressed in relation to a dearly loved pet. When the loved dog or cat seemed secure, the informants felt secure too, or vice versa; if their pet showed signs of insecurity (for example when the dog barked due to unknown staff members visiting at home), this made the patient or family member insecure.

\section{Underlying meanings/themes}

(a) Someone to trust during the threats of the progressive illness

Both the patients and the family members described the patient's unstable, progressive disease as constituting a threat to their sense of security, e.g. through breakthrough symptoms, sudden deterioration or the frightening thought of the forthcoming death. Some of the informants described peaks of feelings of insecurity (e.g. in conjunction with deterioration) and that this feeling faded or was palliated by the trust they felt for an attachment figure.

\section{(b) Made it possible to focus on everyday life}

When the patient/family member felt secure due to the availability of the attachment figure, e.g. through the opportunity to telephone the palliative care unit if needed, they could divert their attention to other things in everyday life, such as socialising with friends, housework or appreciating nature.

I find it as the greatest source of feeling secure, that I have been able to let go some things to the "girls" [nurses and assistant nurses] that come here. I do not need to be there all the time and check, are they doing it right? Because they are competent // I can even go out and pick some 
windfalls or something, or load the washing machine or something. Because I feel secure while they are here (65year-old wife, husband with brain tumour).

\section{(c) Loss of attachment figures}

Some family members described how they had previously felt secure due to their deep relationship with their husband/ wife. However, the progressive disease, e.g. a brain tumour causing changes in personality, had altered him/her so the patient no longer contributed to the family member's sense of security in the same way as before, and this also made them feel a deep loneliness.

Interviewer: What does feeling secure mean to you? Family member: My husband and I are very close and we have been each other's [sources of] security. Once he said to me, "You are my security". But when he is ill, that feeling of security is fading away, he can't give me that any longer (wife of a patient with generalised prostate cancer).

\section{Discussion}

Our study contributes new information about the repertoire of attachment figures during palliative home care, what significance such figures may have, and also that some close family members may suffer the loss of their own attachment figures during this period, if the patient has previously been their source of security, but can no longer be because of the illness.

The results confirm previous findings of adults having multiple attachments, and that family and friends, health care practitioners, pets and God can be attachment figures in the end-oflife context [6, 15-21, 24-27]. Our findings can be interpreted in relation to attachment networks during adulthood. Doherty and Feeney showed that attachment figures differed in relative importance and suggested a sort of hierarchy of significance in attachment figures. For example, the romantic partner, when present, was usually the most salient attachment figure in adult years (i.e. primary attachment figure relied on most and with strongest attachment), but relationships with mothers, fathers, siblings, children and friends also could meet the strict criteria used to define full-blown attachments, i.e. each figure had the capacity to simultaneously fulfil the attachment functions of safe haven, secure base and separation distress [16]. According to our results, health care practitioners in palliative care may also become important parts of patients' as well as family members' attachment networks and be relied on for such attachment function. Attachment networks can be reorganised with changed life situations [16], and the threat of a progressive illness could be such life event.

The patients and family members interviewed stated that when feeling secure (due to trust in their attachment network), they could divert their attention from the threats of the patient's illness to other things in everyday life, e.g. housework, socialising with family and friends or appreciating nature. From an attachment theory perspective, this can be interpreted as the attachment needs having been met and the attachment system deactivated by the certainty that an attachment figure - e.g. a partner, family member, friend or health care practitioner - is available and would be responsive when called upon, allowing the patients/family members to feel secure enough to allocate attention to matters other than self-protection, explore their environment confidently and engage rewardingly with other people $[2,32]$.

Attachment needs and choice of attachment figures may, however, be different depending on attachment style [14, 33]. For example, secure adolescents tend to prefer parents as attachment figures, whereas those with insecure attachment styles seek attachment figures outside the family [33]. Researchers have described different attachment styles, that is, a person's most chronically accessible working models, to be represented on a continuum based on dimensions of attachment anxiety (fear of rejection and abandonment) and avoidance (discomfort with closeness and dependence on close others) in close relationships [34]. A limitation of this study is that we did not assess with a validated instrument each participant's attachment style. Although our global impression, based on the interviews, was that most participants likely had secure attachment styles, some interviews also revealed dimensions of anxiety and/or avoidance, indicating a spectrum of different working models among the participants. For example, a 62-year-old man with advanced prostate cancer with possible avoidant dimensions (we have quoted this informant in a previous publication where we explored palliative home care as a secure base; [4]) described how crucial it had been to his sense of security to have the opportunity of giving himself morphine injections to relieve pain to be able to get out of bed by himself and put on his trousers by himself. He also described how he felt insecure when not the same staff members visited him at home, and how much it meant to his sense of security to have two assigned nurses, "they sit down and talk to me... not only about me being sick... but about what I have done in my life, what I have been able to do". These findings are in line with Tan's suggestions that individuals with an avoidant (or dismissing) attachment style "may become more open to a supportive relationship when a clinician not only communicate interest and availability but also pays particular respect to their need to retain a sense of autonomy". In the above case exemplified by the team finding a way the patient could feel less dependent for basic needs and manage his clothing by himself, and also by the continuity of two assigned nurses facilitating for him to experience a (more) secure relationship and 
meeting his needs of sensing autonomy by letting him tell them of his former autonomy and achievements [14].

Tan also made suggestions regarding individuals with an anxious (preoccupied) attachment style that feedback from the health care staff "that provides assurance about the predictability of support may be important for them to feel secure and to maintain emotional equilibrium", e.g. "by setting clear limits when staff will be available and for what duration". In future research, it would be interesting to further study needs and attachment networks during palliative home care in relation to attachment styles.

Hence, an essential part of the health care practitioners' planning of the palliative care may be to identify patients' already established attachment figures, as well as those of their closest family members, e.g. by asking "When you are afraid or feel insecure, who or what is a potential source of comfort to you"? Another important aspect may be to strive to develop a trustful relationship with the patient/family member and become an attachment figure to them [6], and this may be possible, as discussed above, also with individuals having insecure attachment styles, although more challenging. Health care practitioners, in addition to responding flexibly and sensitively to the patients' and the family members' individual needs $[4,6]$, could ask as follows: "How can we in the team support you when you feel insecure"?

According to the study results, it also seems important to recognise pets and God as potential attachment figures in the end-of-life-context, and to be aware of the value of respectfully enquiring about the possible faith of patients and family members as a security-enhancing source, even in secular countries like Sweden. In addition, health care practitioners should be aware that some family members may be coping with both the forthcoming death of a loved one and the loss of their own attachment figure (the patient) while the latter is still alive. For example, a husband/wife who for a long time had been able to offer protection and comfort, and to whom the family member has been able to seek proximity in times of need, but who now, due to the progressive disease, is no longer able to provide this.

One result we would also like to draw attention to is that patients/family members felt secure not only due to the physical proximity of the attachment figure, but also when they had access to non-physical contact, e.g. by telephone. These results could be viewed in the light of attachment research regarding the role of mental representations (or symbolic proximity to supportive others) and security priming. Previously, there was an emphasis on the regulation of emotions through maintenance of proximity to attachment figures in times of need, but recently, there has also been more interest shown in their regulation through the activation of mental representations of attachment figures (security priming), e.g. by visualisation of the faces of security enhancing attachment figures $[15,35]$. In adulthood, actual proximity seeking behaviour is not automatically needed, and the response to a threat can instead involve the activation of soothing, comforting mental representations of attachment figures. Such representations can be an alternative means of regulating distress and enabling a sense of security, which support the person to cope effectively with threats - a kind of symbolic proximity to supportive others [2]. Further research could focus on how palliative care units can effectively facilitate the patient's/family member's sense of security by security priming, e.g. interventions using written material with photos of the staff, the telephone number of the unit or (during in-patient care) photos of important family members.

Also worth noting in our findings is the vast difference in the needs the informants expressed regarding continuity of the interaction with the health care practitioners who function as attachment figures. Some of the patients/family members interviewed stated that a high level of continuity involving contact with a small number of staff was of great importance to their sense of security, like the example above regarding a man with possible avoidant attachment. In contrast, for others, the palliative care as a whole represented an attachment figure, and although it was preferable to have contact with fewer staff members, they also felt secure having contact with a higher number. In current health care, resources are limited, and it seems important that palliative care teams are aware of this span of patients' and family members' differences in (expressed) needs regarding staff member continuity, perhaps due to different attachment styles, and that they make informed choices concerning which of the patients/families are in need of a higher degree of continuity and which of them may cope well and feel secure enough despite being involved with a higher number of different members of the care team.

The transferability of our results depends, to some extent, on the length of time a patient normally is within palliative home care. In the present study, most patients had experienced more than 3 months, which is longer than the average patient receives. Although there was large variation (from less than 1 month to more than 3 months), this finding may have consequences on the transferability of the results to settings with briefer services where the staff members have shorter time to develop closer relationships with patients and family members.

In conclusion, this study has identified four types of potential attachment figure during palliative home care, described the significance of such figures to patients and family members, and also shown that some close family members may be experiencing the loss of the patient as their own attachment figure while the patient is still alive. To facilitate patients' and family members' sense of security, deactivation of their attachment system and allocation of attention to matters other than self-protection in the end-of-life context, it seems important that in the planning of care, palliative care teams identify both the patient's and the closest family members' attachment figures, as well as engaging in developing trustful relationships with the patients and their family members. 
Acknowledgements We thank the staff at the participating palliative care units for all help, and the Medical Research Council of Southeast Sweden for financial support (FORSS-5775), The Swedish Society of Medicine (2008-21732) and Linköping University. The funders had no role in carrying out the study or reporting its findings.

\section{Compliance with ethical standards}

Conflict of interest The authors declare that they have no conflict of interest.

Open Access This article is distributed under the terms of the Creative Commons Attribution-NonCommercial 4.0 International License (http:// creativecommons.org/licenses/by-nc/4.0/), which permits any noncommercial use, distribution, and reproduction in any medium, provided you give appropriate credit to the original author(s) and the source, provide a link to the Creative Commons license, and indicate if changes were made.

\section{References}

1. Bowlby J (1997, c 1969) Attachment and loss. Volume 1. Attachment, 2nd edn. Pimlico; London

2. Mikulincer M, Shaver PR (2007) Attachment in adulthood: structure, dynamics, and change. Guildford Press, New York

3. Rodin G, Walsh A, Zimmermann C, Gagliese L, Jones J, Shepherd FA, Moore M, Braun M, Donner A, Mikulincer M (2007) The contribution of attachment security and social support to depressive symptoms in patients with metastatic cancer. Psychooncology 16: 1080-1091

4. Milberg A, Wahlberg R, Jakobsson M, Olsson EC, Olsson M, Friedrichsen M (2012) What is a 'secure base' when death is approaching? A study applying attachment theory to adult patients' and family members' experiences of palliative home care. Psychooncology 21:886-895

5. Milberg A, Friedrichsen M, Jakobsson M, Nilsson EC, Niskala B, Olsson M, Wahlberg R, Krevers B (2014) Patients' sense of security during palliative care-what are the influencing factors? J Pain Symptom Manag 48:45-55

6. Isaksson J, Salander P, Granstrom B, Laurell G (2014) Critical incidents reveal how patients with head and neck cancer construct their "secure base" as a "helping system". J Psychosoc Oncol 32:322-341

7. Mancini AD, Bonanno GA (2012) The persistence of attachment: complicated grief, threat, and reaction times to the deceased's name. J Affect Disord 139:256-263

8. Porter LS, Keefe FJ, Davis D, Rumble M, Scipio C, Garst J (2012) Attachment styles in patients with lung cancer and their spouses: associations with patient and spouse adjustment. Support Care Cancer 20:2459-2466

9. Calvo V, Palmieri A, Marinelli S, Bianco F, Kleinbub JR (2014) Reciprocal empathy and working alliance in terminal oncological illness: the crucial role of patients' attachment style. J Psychosoc Oncol 32:517-534

10. Nicholls W, Hulbert-Williams N, Bramwell R (2014) The role of relationship attachment in psychological adjustment to cancer in patients and caregivers: a systematic review of the literature. Psychooncology 23:1083-1095

11. Hillen MA, de Haes HC, van Tienhoven G, Bijker N, van Laarhoven HW, Vermeulen DM, Smets EM (2015) All eyes on the patient: the influence of oncologists' nonverbal communication on breast cancer patients' trust. Breast Cancer Res Treat 153:161-171
12. Currier JM, Irish JE, Neimeyer RA, Foster JD (2015) Attachment, continuing bonds, and complicated grief following violent loss: testing a moderated model. Death Stud 39:201-210

13. Bowlby J (1988/2003) A secure base: clinical applications of attachment theory. Brunner-Routledge, East Sussex

14. Tan A, Zimmermann C, Rodin G (2005) Interpersonal processes in palliative care: an attachment perspective on the patient-clinician relationship. Palliat Med 19:143-150

15. Mikulincer M, Shaver PR (2007) Boosting attachment security to promote mental health. Prosocial Values, and Inter-Group Tolerance Psychological Inquiry 18:139-156

16. Doherty NA, Feeney JA (2004) The composition of attachment networks throughout the adult years. Pers Relat 11:469-488

17. Petersen Y, Koehler L (2006) Application of attachment theory for psychological support in palliative medicine during the terminal phase. Gerontology 52:111-123

18. Beck M, Madresh EA (2008) Romantic partners and four-legged friends: an extension of attachment theory to relationships with pets. Anthrozoos 21:43-56

19. Granqvist P, Mikulincer M, Shaver PR (2010) Religion as attachment: normative processes and individual differences. Personal Soc Psychol Rev 14:49-59

20. Field NP, Orsini L, Gavish R, Packman W (2009) Role of attachment in response to pet loss. Death Stud 33:334-355

21. Kurdek LA (2009) Pet dogs as attachment figures for adult owners. J Fam Psychol 23:439-446

22. Rochman D (2013) Death-related versus fond memories of a deceased attachment figure: examining emotional arousal. Death Stud 37:704-724

23. Cicirelli VG (2004) God as the ultimate attachment figure for older adults. Attach Hum Dev 6:371-388

24. Adshead G (1998) Psychiatric staff as attachment figures. Understanding management problems in psychiatric services in the light of attachment theory. Br J Psychiatry 172:64-69

25. Spetz A, Henriksson R, Salander P (2008) A specialist nurse as a resource for family members to patients with brain tumors: an action research study. Cancer Nurs 31:E18-E26

26. Gerretsen P, Myers J (2008) The physician: a secure base. J Clin Oncol 26:5294-5296

27. Wright EB, Holcombe C, Salmon P (2004) Doctors' communication of trust, care, and respect in breast cancer: qualitative study. BMJ 328:864

28. Hsieh H-F, Shannon SE (2005) Three approaches to qualitative content analysis. Qual Health Res 15:1277-1288

29. Svenska Akademiens Ordbok [Dictionnary of the Swedish Academy] http://g3.spraakdata.gu.se/saob/. Accessed 13 July 2015

30. Graneheim UH, Lundman B (2004) Qualitative content analysis in nursing research: concepts, procedures and measures to achieve trustworthiness. Nurse Educ Today 24:105-112

31. Malterud K (2001) Qualitative research: standards, challenges, and guidelines. Lancet 358:483-488

32. Luke MA, Sedikides C, Carnelley K (2012) Your love lifts me higher! The energizing quality of secure relationships. Personal Soc Psychol Bull 38:721-733

33. Freeman H, Brown BB (2001) Primary attachment to parents and peers during adolescence: differences by attachment style. Journal of Youth and Adolescence 30:653-674

34. Lo C, Walsh A, Mikulincer M, Gagliese L, Zimmermann C, Rodin G (2009) Measuring attachment security in patients with advanced cancer: psychometric properties of a modified and brief experiences in close relationships scale. Psychooncology 18:490-499

35. Mikulincer M, Shaver PR, Rom E (2011) The effects of implicit and explicit security priming on creative problem solving. Cognit Emot 25:519-531 